\title{
Current and emerging therapeutic strategies for Fanconi anemia
}

\author{
Pallavi Shukla, Kanjaksha Ghosh and Babu R Vundinti
}

\begin{abstract}
Fanconi Anemia (FA) is a rare disorder with incidence of 1 in 350,000 births. It is characterized by progressive bone marrow failure leading to death of many patients in their childhood while development of cancer at later stages of life in some. The treatment of FA is still a medical challenge. Current treatments of FA include androgen administration, hematopoietic growth factors administration and hematopoietic stem cell transplantation (HSCT). Clinical gene therapy trials are still ongoing. The partial success of current therapies has renewed interest in the search for new treatments. Generation of patient-specific induced pluripotent stem (iPS) has shown promising results for cell and gene based therapy. Small molecule interventions have been observed to delay tumor onset in FA. Tumors deficient in FA pathway can be treated by profiling of DNA repair pathway through synthetic lethality mechanism. Targeting toll-like receptor 8 (TLR8) dependent TNF $\alpha$ overexpression is yet another upcoming therapeutic approach to treat FA patients. In conclusion, in the present scenario of treatments available for FA, a proper algorithm of treatment decisions must be followed for better management of FA patients and to ensure their increased survival. Innovative therapeutic approaches that can prevent both anemia and cancer should be developed for more effective treatment of FA.
\end{abstract}

Keywords: Fanconi Anemia, Androgens, Haematopoitic growth factors, Haematopoietic stem cell transplantation, Gene therapy, Small molecule intervention, DNA repair pathway

\section{Introduction}

Fanconi anemia (FA) is an autosomal recessive disorder (OMIM 227650). It is characterized by bone marrow failure (aplastic anemia), developmental delay, physical abnormalities such as short stature; microcephaly; abnormal skin pigmentation; malformations of skeletal system, limbs, eyes, ears, kidneys and urinary tract, heart, genitalia, gastrointestinal system and central nervous system; and increased incidence of solid tumors and leukemias (Auerbach et al. 2001; D'Andrea and Grompe 1997). To date, around 14 genes are responsible for known complementation FA groups: A, B, C, D1 [BRCA2], D2, E, F, G, I, J [BRIP1], L, M, N [PALB2] and $P$ [SLX4] are known. There are three other genes RAD51C, DDX11, FAAP20 which are involved in the pathway, but not formally designated as FA genes (Svahn and Dufour 2011). FA proteins play an important role in repair of DNA damage. When DNA damage occurs, the FA proteins, A, B, C, E, F, G, I, L, and $\mathrm{M}$ at

* Correspondence: vbaburao@hotmail.com

National Institute of Immunohaematology (NIIH), Mumbai, India upstream of the pathway monoubiquitinate FANCD2 protein, resulting in targeting of protein in nuclear foci. FANCD2 then interacts with BRCA1 and other DNA damage response proteins downstream of the FA pathway such as BRCA2, RAD51 and NBS to repair the damage (Wang et al. 2004) (Figure 1). Alterations in FA-pathway proteins has also been reported in various types of cancers such as breast cancer, ovarian cancer, lung cancer, cervical cancer, pancreatic cancer etc (Dhillon et al. 2004; Marsit et al. 2004, Narayan et al. 2004; Taniguchi et al. 2003; van Der Heijden et al. 2003). Thus, FA proteins take part in DNA damage repair directly or indirectly. Indirect role of FA proteins in repairing the DNA damage is by triggering a cell cycle checkpoint (Sala-Trepat et al. 2000).

FA proteins are also known to interact with other proteins such as FANCA and FANCC with $\alpha$ spectrin II; FANCC with cytochrome P-450 reductase and with glutathione S-transferase, Hsp70, STAT1; and FANCG with cytochrome P-450 2E1 (McMahon et al. 1999; Pagano and Youssoufian, 2003; Pang et al. 2000; Futaki et al. 


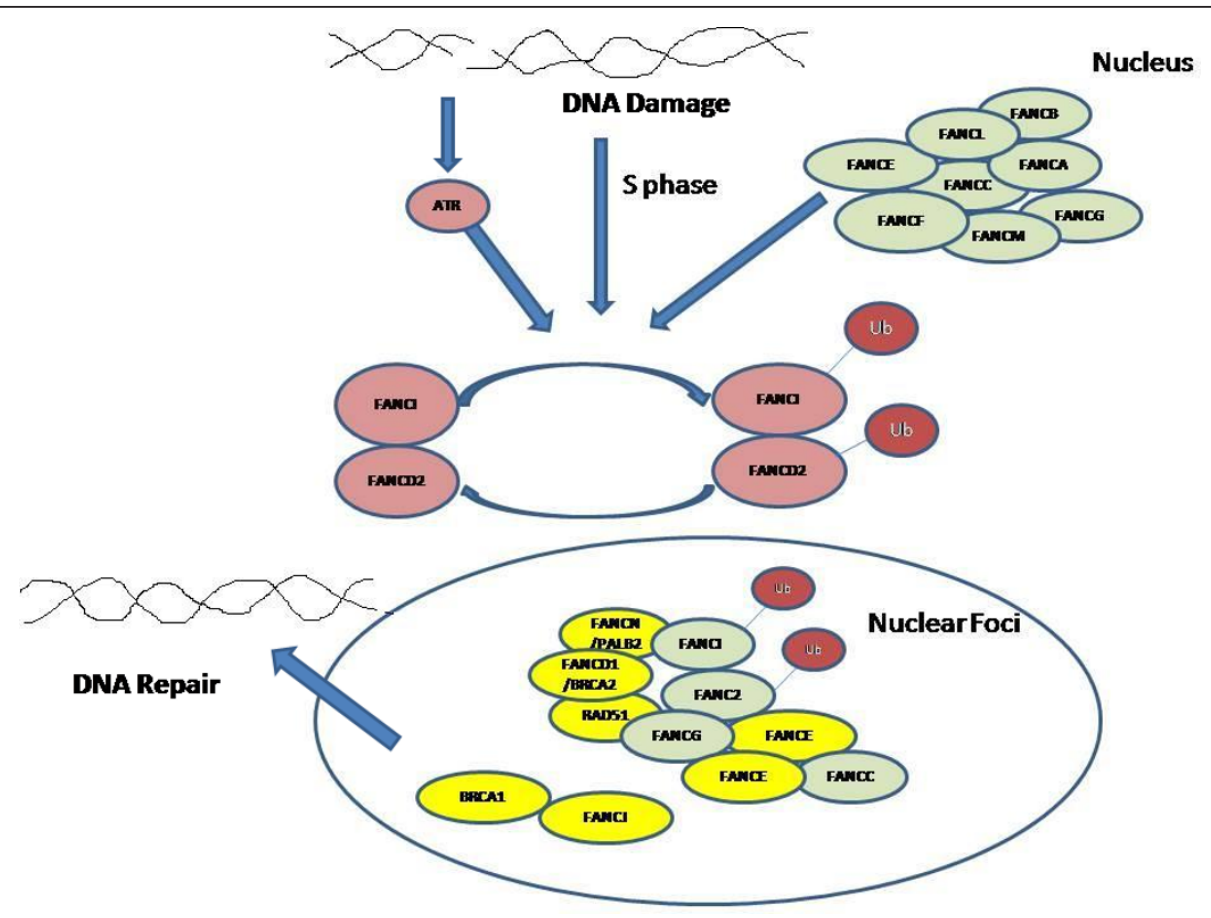

Figure 1 FA/BRCA pathway showing role of Fanconi Anemia proteins in DNA damage repair

2002). Interactions with these proteins suggest the diverse role of FA proteins in a number of cellular processes, such as DNA synthesis, cell cycle progression, gene expression, signal transduction, cell growth and differentiation, and protection against oxidative DNA damage. This could possibly explain some of the diverse cellular defects such as cell cycle defects, aberrant induction of apoptosis, and clinical heterogeneity reported in FA.

Presently the available treatments for FA are androgen administration, administration of hematopoietic growth factors and bone marrow transplantation. Clinical Gene therapy trials still have a long way to go. Small molecule intervention, controlling TNF $\alpha$ overproduction and profiling of DNA damage repair pathway are the new emerging therapies under investigation. This review highlights the current treatments available for FA and discusses new and emerging therapeutic strategies that can be exploited for the treatment of FA in future.

\section{Current treatments}

\section{Androgen administration}

Androgens are male hormones (many aren't artificial) that stimulate production of red blood cell count, platelets, and white blood cells in some FA patients. Oxymetholone, a 17-a-alkylated androgen is the most common androgen used in the treatment of FA patients. Use of androgens has many pitfalls. Androgens are not a permanent cure, but only prolong the life of patients.
Patients response to androgens only if the treatment is started at early stage. Though $70 \%$ of the patients respond to androgens, the response is slow, drug dependent and incomplete. Other limitations include several side effects such as masculinisation, acne, growth spurt and premature closing of epiphysis and risk to liver tumours (Moldvay et al. 1991; Mulvihill et al. 1975; Ozenne et al. 2008; Touraine et al. 1993). Thus, in case of androgen therapy, follow up of patient has to be done for evaluation of liver function test (enzymes, bilirubin) and ultrasound examination. Androgens are also reported to adversely affect the outcome of subsequent haematopoietic stem cell transplantation (HSCT) in some studies (Dufour et al. 2008). In view of these limitations of androgens, the treatment is recommended for FA patients with aplastic anemia for whom there is no acceptable hematopoietic stem cell transplant donor available (Velazquez and Alter 2004).

\section{Hematopoietic growth factors}

Hematopoietic growth factors (HGFs) bind with high affinity to specific receptors expressed on the surface of the target cells and stimulate primitive hematopoietic stem and progenitor cells as well as activate some mature cells.

Several growth factors such as recombinant (rh) interleukin (IL)-3 and granulocyte-macrophage colony-stimulating factor (rhGM-CSF), granulocyte colonystimulating factor (rhG-CSF), have been used in human 
trials with FA patients (Gillio and Gabrilove 1993; Guinan et al. 1994; Rackoff et al. 1996). Administration of rhGM-CSF raises the neutrophil count in most pancytopenic patients, but the platelet count and haemoglobin concentration are generally unaffected. Thus, rhGMCSF therapy can be used for stabilizing neutropenic complications of the disease (Rackoff et al. 1996). A study on fancc ${ }^{-1-}$ mouse model showed that the short term use of G-CSF either alone or in combination with erythropoietin increased the peripheral blood count and delays the mitomycin $C$ (MMC) induced bone marrow failure, but its long term administration leads to increased sensitivity to MMC and bone marrow hypoplasia. A study demonstrated that FANCC binds to STAT1 and facilitates its activation by gamma interferon and hematopoietic growth factors (Pang et al. 2000).

Due to the limited success of the preliminary results, clinical trials of HGFs administration have not been carried out so far. Moreover, cytokine use is not recommended for patients with a clonal cytogenetic abnormality. Further studies are therefore needed to search novel cytokines and to establish the long-term efficacy of HGFs and their impact on progression of FA to acute myeloid leukaemia (AML) or myelodysplasia.

\section{Bone marrow transplantation}

Bone marrow transplantation (BMT) or HSCT is the only curative therapy for marrow failure in FA patients. Early attempts with BMT for the treatment of marrow failure had a limited success as excessive regimenrelated toxicity, graft failure, and severe acute graft-versus-host disease (GVHD) leads to high mortality rate (Davies et al. 1996; Gluckman et al. 1995; Wagner et al. 2003). There is also a risk of developing solid tumours at later stages after the hematopoietic stem cell transplantation. As FA cells are hypersensitive to DNA cross linking agents, FA patients exhibit increased sensitivity to exposure to use of cyclophosphamide $(\mathrm{CY})$ or irradiation. Thus different chemotherapy and radiation regimens were proposed to lower the adverse effect in the BMT treatment on FA patients. Gluckman et al in 1983 demonstrated that low-dose cyclophosphamide and thoracoabdominal irradiation be used as the conditioning regimen for FA patients for BMT treatment (Gluckman et al. 1983). Use of low-dose cyclophosphamide and thoracoabdominal irradiation was also supported by other study in which 58\% survival of patients over 100 months was reported (Socié et al. 1998). However this reduced intensity conditioning regimen was found to be unsuccessful for consistent engraftment in recipients of unrelated donor BMT (Gluckman et al. 1983, Guardiola et al. 2000; Wagner et al. 2003). Later MacMillan et al showed that the high rate of graft failure occurs in patients with $\mathrm{T}$ cell mosaicism and a standard therapy regimen consisting of cyclophosphamide $(\mathrm{CY})$, total body irradiation (TBI), and anti-thymocyte globulin (ATG) was insufficient to eradicate DEB-resistant $\mathrm{T}$ cells (MacMillan et al. 2011). Further studies confirmed that the use of fludarabine in the preparative therapy increases the overall survival rate of patients undergoing BMT (Kapelushnik et al. 1997; MacMillan et al. 2005; Wagner et al. 2007). Addition of fludarabine in the therapy regimen was also reported to overcome the high frequency of graft rejection due to incomplete ablation of DEB-resistant lymphocytes in somatic mosaic FA patients (Wagner et al. 2007).

It was also demonstrated that in case of unrelated donor BMT, in which GVHD is the major limitation, the combined therapy of fludarabine-based preparatory regimens and $T$-cell depletion reduces the risk of GVHD and increases the overall survival (Bitan et al. 2006; Drobyski 2000). Because GVHD has been associated with an increased risk of malignancy in patients, strategies to reduce the risk of GVHD and improve overall survival have been developed. In an attempt to decrease the risk and severity of regimen-related toxicities, Pasquini and group in 2008 studied outcomes of HSCT in 148 FA patients after irradiation and non-irradiation regimens and found that hematopoietic recovery, acute and chronic GVHD and mortality were similar in both regimens (Pasquini et al. 2008). Gluckman and Wagner in the recent review have proposed that HLAidentical sibling hematopoietic stem cell transplantation should be performed as first-line therapy, without first using androgens or corticosteroids due to their side effects. They also proposed that the best conditioning regimen is combination of fludarabine-containing regimens with low-dose cyclophosphamide $(\mathrm{CY})$ or $\mathrm{Bu}$ and antithymocyte globulin (ATG). This regimen was found to overcome rejection in patients receiving multiple transfusions, limit early and late toxicities and minimize risk of GVHD (Gluckman and Wagner 2008). Recently, MacMillan et al demonstrated that sufficient engraftment is possible with minimum of $300 \mathrm{cGy}$ Total body Irradiation (TBI) in recipients of cyclophosphamide- fludarabine-antithymocyte globulin therapy and HLA matched or mismatched $\mathrm{T}$ cell-depleted alternative donor BM or unmanipulated umbilical cord blood (MacMillan et al. 2009).

Though the HSCT has been successful in increasing the overall survival rate of patients but unfortunately occurrence of cancer has been observed in long-term survivors. In a study of a retrospective cohort of 145 North American FA patients, the crude rate for solid tumors prior to BMT, AML, or death was $0.7 \%$ per year, whereas the rate was $1.99 \%$ after BMT (Rosenberg et al. 2003). In 2005, Rosenberg reported that the incidence of squamous cell carcinoma (SCC) was 4.4-fold 
higher in FA patients who received transplants than in those who did not, and SCCs occurred at significantly younger ages in the former (Rosenberg et al. 2005).

The lack of HLA matched donor due to small families is the limitation in HSCT. However, preimplantation genetic diagnosis (PGD) facilities by umblical cord blood as an alternative source of hematopoietic stem cells provide a novel option in such case (Bielorai et al. 2004, Grewal et al. 2004; Verlinsky et al. 2001). The use of PGD for combined analysis of mutation and HLA matching enables the birth of an unaffected child who can serve as a potential donor for an affected sibling in need for stem cell transplantation. PGD uses standard assisted reproduction technologies and requires the biopsy of material from either the oocyte and/or the developing embryo. The biopsied material tested for the genetic defect and HLA match unaffected embryos is transferred to the uterus. At the time of birth of a child, cord blood cells are harvested and used for HSCT. However, the technique has some disadvantages such as low success rate, health risk and financial and emotional burden involved with the procedure. In addition, a number of families undergoing PGD had experienced repeated unsuccessful PGD cycles (Schindler and Hoehen 2007).

Thus, despite recent advances in the BMT that have lead to an increase in the overall survival rate of FA patients, there is still a need to establish new therapies for proper and cost effective treatment of FA.

\section{Future therapies \\ Gene Therapy}

Transduction of fibroblasts, lymphoblastoid cells, or hematopoietic cells from FA patients using retroviral vector containing the CDNA for FANCA has shown that ex-vivo gene transfer is feasible as a treatment for the hematopoietic defects observed in FA (Cohen-Haguenauer et al. 2006). However, to increase the efficiency of gene transfer, it requires sufficient numbers of hematopoietic stem/progenitors cells from FA patients that are difficult to obtain (Croop et al. 2001). Moreover, ex vivo culture for gene transfer is deleterious to FA cells and may be responsible for the poor success rate of earlier gene therapy trials in FA patients (Aube et al. 2002; Habi et al. 2005; Liu et al. 1999). FA patient cells do not survive well in ex vivo culture due to their sensitivity to oxygen mediated damage, though the cells successfully grow in a low oxygen environment. Clinical trial of retrovirus-mediated gene transfer in FANCA patients was not successful, because durable engraftment of genemodified cells could not be achieved (Kelly et al. 2007). Recent studies demonstrating gene therapy using lentiviral vectors seems to be promising due to shorter transduction time, minimizing ex vivo culture, and high level transgene expression in hematopoietic cells. Another advantage of lentiviral vectors is that they do not integrate close to the promoters of transcriptionally active genes as frequently as gammaretroviral vectors do, and therefore reduces the insertional mutagenesis, and the risk of vector-mediated dysregulation of nearby genes (Beard et al. 2007). Various studies of gene therapy using lentiviral vectors have been reported. Becker and co-workers demonstrated that lentiviral transduction of CD34 cells, with ex vivo cell culture in the presence of low oxygen (5\%), reducing agent $\mathrm{N}$-acetyl-Lcysteine (NAC), and a combination of growth factors improves viability and engraftment potential of human cells (Becker et al. 2010). Habi and group have demonstrated that long-term expression of the Fancc transgene can be achieved by a direct in vivo gene transfer approach using lentiviral vector to deliver the FanccEGFP transgene. Transduced stem and progenitor cells were functionally corrected for their MMC sensitivity thus showing that the inserted transgene is functional in correcting this defect. In addition, mice intrafemorally injected with the Fancc-EGFP transgene were resistant to the MMC-induced progressive BM failure (Habi et al. 2010).

Future trials of gene therapy are strengthened by the fact that some FA patients are mosaic where a subgroup of cells is negative for $\mathrm{DEB} / \mathrm{MMC}$ test while others are positive. Somatic mosaicism occurs due to the reversion of a pathogenic allele to 'wild' type in a single somatic cell and leads to the generation of normal functional allele, resulting in the growth/survival advantage of the corrected cell in the background of FA cells. The clinical implications of revertant mosaicism depend on the developmental stage, blood cell lineage affected by the reversion event and the clinical situation of the mosaic patient (Hoehn et al. 2007). In self renewing tissues, the reversion event may convey a growth advantage to the revertant cells leading to the ultimate replacement of the defective cells. The mechanisms of the natural gene therapy vary and involve mitotic crossover, gene conversion, back mutation or second site mutation (Hoehn et al. 2007). Depending on the mechanism of somatic reversion, the function of affected cell lineage may be partly or completely restored (Gross et al. 2002).

In a recent review, International FA Gene Therapy Working Group has proposed an optimal strategy for conducting stem cell gene therapy clinical trials in FA (Tolar et al. 2011). The group has recommend HIV-1 derived self inactivating lentiviral vectors as the most suitable vector for initial phase I clinical trial for gene correction in fanconi anemia. For FANCA gene therapy, Phosphoglycerate kinase (PGK) promoter in combination with an optimized woodchuck hepatitis virus posttranscriptional regulatory element (WPRE) based 
lentiviral vectors are useful since the combination ensures stable transgene expression and low genotoxicity. The group advises use of purified grafts from FA bone marrow, or mobilized peripheral blood cells and recommends for hematopoetic harvest at early stages of the disease to obtain sufficient numbers of hematopoietic stem/progenitors cells. Major inclusion and exclusion criteria for gene therapy clinical trial in patients with bialleleic FANCA germ line mutations were also proposed (Table 1). Conducting multi-centre gene therapy protocols using this design will further provide a framework for establishing next generation clinical trials using various modifications.

Recently, generation of patient-specific induced pluripotent stem (iPS) has shown a great therapeutic potential to obtain disease corrected patient specific cells (Raya et al. 2009). This observation has wider applications in cell and gene therapy and can help in overcoming the limitation of gene therapy, insertional oncogenesis and lack of hematopoietic stem cells. Like embryonic stem (ES) cells, human iPS cells can differentiate to any cell lineage in the body; and genetically corrected iPS cells specifically target safe integration sites of the therapeutic transgenes. Raya et al in 2009 showed that on the introduction of wild-type transgene, reprogramming efficiency is restored but endogenous FA mutation carrying iPS cells may be generated and subsequent knockdown of the correcting transgene led to rapid loss of self-renewal. This suggests that an intact FA pathway is required for induction and maintenance of pluripotency (Raya et al. 2009). However, it may be possible that disruption of the DNA repair machinery in FA cells precludes resolution of the DNA breaks that occurs due to the reprogramming protocol with retroviral/lentiviral integration. Thus using nonintegrating transgenes for reprogramming may permit the generation of genetic lesion free FA iPS cells and can also be propagated continuously. Further studies will be

Table 1 Major inclusion and exclusion criteria for gene therapy in patients with biallelic FANCA germ-line mutations as proposed by International Fanconi Anemia Gene Therapy Working Group.

\begin{tabular}{|c|c|}
\hline \multirow[t]{2}{*}{$\begin{array}{l}\text { Inclusion } \\
\text { Criteria }\end{array}$} & $\begin{array}{l}\text { 1. FA demonstrated by a positive test for increased } \\
\text { sensitivity to chromosomal breakage with MMC/DEB } \\
\text { and determination of FA complementation group A by } \\
\text { somatic cell hybrids, molecular characterization, western } \\
\text { blot analysis, direct FANCA sequencing, or acquisition } \\
\text { of mitomycin C resistance after in vitro transduction } \\
\text { with a vector bearing the FANCA CDNA. }\end{array}$ \\
\hline & $\begin{array}{l}\text { 2. Bone Marrow analysis demonstrating normal } \\
\text { karyotype. }\end{array}$ \\
\hline \multirow[t]{2}{*}{$\begin{array}{l}\text { Exclusion } \\
\text { Criteria }\end{array}$} & 1. Uncontrolled infection (viral, bacterial, or fungal). \\
\hline & 2. Patients with an HLA identical sibling donor. \\
\hline
\end{tabular}

required to elucidate the precise role of the FA pathway in induction and maintenance of pluripotency (MacMillan et al. 2011). Other limitations of IPS cells that need to be addressed are chromosome abnormalities, differences in gene expression and epigenetic state, obtaining pure cell population and immunologic rejection in autologous transplantation in mice (Nordin et al. 2011).

\section{New emerging Therapies}

Small molecule intervention, targeting TLR8 pathway to suppress TNF $\alpha$ production and profiling DNA damage repair pathways are new exciting emerging therapies under research.

Traditional methods have been successful in preventing anemia however they could not prevent the occurrence of cancer at later stages of life in FA patient. Thus a small molecule that can prevent both anemia and cancer will be an ideal therapy for FA. The best solution will be the prevention of DNA damage or DNA repair. Since FA cells are known to be hypersensitive to reactive oxygen species (ROS) that can damage the DNA and therefore cause mutation and cancer ( $\mathrm{Du}$ et al. 2008; Muller and Williams 2009), treatment with antioxidants can reduce oxidative DNA damage and thus has the potential to delay cancer in FA. First small molecule tested in FANCD2 mice was Tempol (4-hydroxy-2,2,6,6 tetramethyl piperidine- $\mathrm{N}$-oxyl), a nitroxide antioxidant and a superoxide dismutase mimetic; it was found to delay epithelia tumor onset (Zhang et al. 2008). Moreover, it did not adversely affect the repopulating capability of FA hematopoietic stem cells. Treatment with the antioxidant drug, resveratrol, an activator of SirT1 deacetylase, was demonstrated to partially correct hematopoietic defects in Fancd2 $2^{-/-}$mice (Zhang et al. 2010). Similarly, other molecules such as $\mathrm{N}$-acetyl cystine and chloroquine may also be tested for their therapeutic potential in treating FA.

By High-Throughput cell screening, potential small molecule inhibitors of FA/BRCA pathway such as wortmannin, H-9, and alsterpaulone and curcumin were identified (Chirnomas et al. 2006) in which curcumin, a natural compound was found to be most suitable inhibitor because it is less toxic and thus safe to administer.

Another developing field of investigation for FA therapy is TLR8 pathway dependent TNF- $\alpha$ overproduction. $\mathrm{TNF} \alpha$, a molecule which plays a direct role in the pathogenesis of both bone marrow failure and clonal evolution in Fancc ${ }^{-/}$mice (Li J. et al. 2007). In marrow failure, hypersensitivity to TNF $\alpha$ is exacerbated by the overproduction of TNF $\alpha$ by FA cells, (Dufour C et al. 2003) which is controlled by both transcriptional and posttranslational mechanisms that require activation of MAPK pathways (Briot D et al. 2008). It was found that TLR8 (or a TLR8-associated protein) is highly 
ubiquitinylated in mutant FA-C cells and that overproduction of TNFa in mutant cells depends on TLR8. Studies using THP-1 blue shFANCC cells indicate that a major mechanism by which p38 influences TNF $\alpha$ production is by suppressing TNF $\alpha$ gene transcription. Other potential binding partners of TLR8 include MyD88, Mal, IRAK4, IRAK1, and other TLRs (TLR7 and TLR9) (O'Neill LA. 2008). TLR8 may also bind to negative regulators, SIGIRR, ST2L, MyD88s, SOCS1, Tollip, IRAKM, IRAK2c/d, and TRIAD3A. All these proteins should be considered as possible targets for this key posttranslational modification. Thus TLR8 pathway represents a potentially attractive developmental therapeutic target in FA for high-throughput screening for molecules that activates/inactivates this pathway in FA$\mathrm{C}$ cells, and the THP-1 Blue/FANCC shRNA cells provide a convenient tool for the screening.

FA patients have an increased risk of developing tumours, myelodysplastic syndromes (MDS) and acute myeloid leukaemia (AML), suggesting that the FA proteins take part in DNA damage repair. Profiling of DNA repair pathway through synthetic lethality mechanism can be applicable as therapeutic approach for FA pathway deficient tumours. There are various DNA repair pathways; base excision repair (BER), nucleotide excision repair (NER), mismatch repair (MMR), homologous recombination (HR), nonhomologous end-joining (NHEJ), and translesion DNA synthesis (TLS) in the cell that plays a role when DNA damage occurs, depending upon its type. All FA proteins interact in a common pathway involving in homologous recombination. Loss of one DNA repair pathway may result in hyper-dependence on a second, compensatory DNA repair pathway. For example, cancer cells with a mutated FA pathway may be hyperdependent on the BER, NHEJ or TLS pathway (D'Andrea 2010; Tutt et al. 2001). Therefore, in FA patients, tumours with defect in FA pathway can be treated by inhibiting this second pathway. The idea is to find a drug that can target the second pathway and can effectively kill the cancer cell. For example, FA deficient tumour cells are known to be hypersensitive to the inhibition of CHK1, particularly when combined with cisplatin therapy (Chen et al. 2009). Moreover, if the FA pathway serves as a backup for some other pathway, inhibition of such a pathway will lead to the activation of the FA pathway and thus be detrimental in FA pathway deficient cells (Evers et al. 2010). For example, Poly-ADP-ribose polymerase-1 (PARP-1) is involved in base excision repair, a pathway repairing DNA singlestrand breaks (SSB). Loss of PARP1 leads to the conversion of SSBs to double-strand breaks (DSBs) and increases the demand for HR repair pathway. Utilizing PARP inhibitors may therefore be a successful therapeutic strategy for a subset of AML patients with deficient in HR such as FA deficient pathway or deficient in RAD51 loci (D'Andrea 2010).

In future, identification of the new partners of the FA pathway as well as other DNA damage repair pathways, understanding the crosstalk between these pathways and the mechanism of their regulation will help in generating new small inhibitor molecules that can act as drug target in devising a promising therapeutic strategy for targeting DNA damage repair pathways.

To conclude, since the FA clinical trials are undergoing and research for a better therapeutic approach is underway, so in the present scenario, a proper algorithm based on the available established treatments and recent scientific advances should be devised for the treatment of the FA. If the clinical diagnosis has been done on the basis of physical abnormalities, bone marrow failure, haematopoiesis and organ abnormalities or cancer, first step should be to perform the chromosome breakage test. If the test is positive, molecular analysis through FANCD2 western blot can be done to confirm the diagnosis and to classify the patients according to FA/BRCA pathway. The patient should then be tested for complementation analysis and mutation testing. Relatives also need to be checked for chromosome fragility and mutation analysis. Histocompatibility antigen (HLA) typing should be done for stem cell transplantation. If HLA matched and non FA donor is available in the family, HSCT can be the first line of action. However, as the risk of graft failure increases in transfusions, transplantation should be performed before the patient is transfused. If HLA matched donor cannot be found then search for unrelated HLA matched donor should be started. Until the donor is found, androgens and growth factors will be good holding treatment to delay haematopoietic stem cell depletion. If the search for unrelated donor is still not successful, then in vitro fertilization, PGD and HSCT using umbilical cord blood collection may be a choice. However, it should be noted that HSCT treatment using HLA matched or unrelated donor has shown only marginal difference in the survival rate of the patient. Three year overall survival after HSCT in recipients of FA-negative HLA matched sibling grafts was $69-93 \%$ whereas using alternative donor grafts survival was 52-88\%, (MacMillan et al. 2010; Wagner et al. 2007; Farzin, et al. 2007). Finally, gene therapy can also be considered for the treatment.

\section{Authors' contributions}

PS has reviewed the literature and drafted the manuscript. KG and BV participated in designing the manuscript and editing the manuscript. All authors read and approved the final manuscript.

Competing interests

The authors declare that they have no competing interests. 
Received: 7 September 2011 Accepted: 9 March 2012

Published: 9 March 2012

\section{References}

Aube M, Lafrance M, Charbonneau C, Goulet I, Carreau M (2002) Hematopoietic stem cells from FancC-/- mice have lower growth and differentiation potential in response to growth factors. Stem Cells 20:438-447. doi:10.1634/ stemcells.20-5-438.

Auerbach A, Buchwald M, Joenje H (2001) Fanconi Anemi. In: Scriver CR, Beaudet AL, Sly WS, Valle D (ed) The Metabolic and Molecular Bases of Inherited Disease, 8th edn. MacGraw-Hill, NewYork pp 753-768

Beard BC, Keyser KA, Trobridge GD, Peterson LJ, Miller DG, Jacobs M, Kaul R, Kiem HP (2007) Unique integration profiles in a canine model of long-term repopulating cells transduced with gammaretrovirus, lentivirus, or foamy virus. Hum Gene Ther 18:423-434. doi:10.1089/hum.2007.011.

Becker PS, Taylor JA, Trobridge GD., et al (2010) Preclinical correction of human Fanconi anemia complementation group A bone marrow cells using a safety-modified lentiviral vector. Gene Therapy 17:1244-1252. doi:10.1038/ gt.2010.62.

Bielorai B, Hughes MR, Auerbach AD., et al (2004) Successful umbilical cord blood transplantation for Fanconi anemia using preimplantation genetic diagnosis for HLA-matched donor. Am J Hematol 77:397-399. doi:10.1002/ ajh.20201.

Bitan M, Or R, Shapira MY, Aker M, Resnick IB, Ackerstein A, Samuel S, Elad S, Slavin S (2006) Fludarabine-based reduced intensity conditioning for stem cell transplantation of Fanconi anemia patients from fully matched related and unrelated donors. Biol Blood Marrow Transplant 12:712-718. doi:10.1016/ j.bbmt.2006.03.002.

Briot D, Mace'-Aime' G, Subra F, Rosselli F (2008) Aberrant activation of stressresponse pathways leads to TNF-a oversecretion in Fanconi anemia. Blood 111:1913-1923. doi:10.1182/blood-2007-07-099218.

Chen CC, Kennedy RD, Sidi S, Look AT, D'Andrea A (2009) CHK1 inhibition as a strategy for targeting Fanconi Anemia (FA) DNA repair pathway deficient tumors. Mol Cancer 8:24-39. doi:10.1186/1476-4598-8-24.

Chirnomas D, Taniguchi T, de la Vega M., et al (2006) Chemosensitization to cisplatin by inhibitors of the Fanconi anemia/BRCA pathway. Mol Cancer Ther 5:952-961. doi:10.1158/1535-7163.MCT-05-0493.

Cohen-Haguenauer O, Péault B, Bauche C., et al (2006) In vivo repopulation ability of genetically corrected bone marrow cells from Fanconi anemia patients. Proc Natl Acad Sci USA 103:2340-2345. doi:10.1073/ pnas.0510613103.

Croop JM, Cooper R, Fernandez C., et al (2001) Mobilization and collection of peripheral blood CD34+ cells from patients with Fanconi anemia. Blood 98:2917-2921. doi:10.1182/blood.V98.10.2917.

D'Andrea AD, Grompe M (1997) Molecular biology of Fanconi anemia: implications for diagnosis and therapy. Blood 90:1725-1736

D'Andrea AD (2010) Targeting DNA repair pathways in AML. Best Pract Res Clin Haematol 23:469-473. doi:10.1016/j.beha.2010.09.005.

Davies SM, Khan S, Wagner JE., et al (1996) Unrelated donor bone marrow transplantation for Fanconi anemia. Bone Marrow Transplant 17:43-47

Dhillon VS, Shahid M, Husain SA (2004) CpG methylation of the FHIT FANCF, cyclin-D2, BRCA2 and RUNX3 genes in Granulosa cell tumors (GCTs) of ovarian origin. Mol Cancer 3:33-40. doi:10.1186/1476-4598-3-33.

Drobyski WR (2000) Evolving strategies to address adverse transplant outcomes associated with T cell depletion. J Hematother Stem Cell Res 9:327-337. doi:10.1089/15258160050079434.

Du W, Adam Z, Rani R, Zhang X, Pang Q (2008) Oxidative stress in Fanconi anemia hematopoiesis and disease progression. Antioxid Redox Signal 10:1909-1921. doi:10.1089/ars.2008.2129.

Dufour C, Corcione A, Svahn J., et al (2003) TNFa and IFN $\gamma$ are overexpressed in the bone marrow of Fanconi anemia patients and TNF-a suppresses erythropoiesis in vitro. Blood 102:2053-2059. doi:10.1182/blood-2003-01-0114.

Dufour C, Svahn J (2008) Fanconi anaemia: new strategies. Bone Marrow Transplant 41(Suppl 2):S90-5

Evers B, Helleday T, Jonker J (2010) Targeting homologous recombination repair defects in cancer. Trends Pharmacol Sci 31:372-380. doi:10.1016/j. tips.2010.06.001.

Farzin A, Davies SM, Smith FO., et al (2007) Matched sibling donor haematopoietic stem cell transplantation in Fanconi anaemia: an update of the Cincinnati Children's experience. Br J Haematol 136:633-640. doi:10.1111/ j.1365-2141.2006.06460.x
Futaki M, Igarashi T, Watanabe S., et al (2002) The FANCG Fanconi anemia protein interacts with CYP2E1: possible role in protection against oxidative DNA damage. Carcinogenesis 23:67-72. doi:10.1093/carcin/23.1.67.

Gillio AP, Gabrilove JL (1993) Cytokine treatment of inherited bone marrow failure syndromes. Blood 81:1669

Gluckman E, Auerbach AD, Horowitz MM., et al (1995) Bone marrow transplantation for Fanconi anemia. Blood 86:2856-2862

Gluckman E, Devergie A, Dutreix J (1983) Radiosensitivity in Fanconi anaemia: application to the conditioning regimen for bone marrow transplantation. $\mathrm{Br}$ J Haematol 54:431-440. doi:10.1111/j.1365-2141.1983.tb02117.x.

Gluckman E, Wagner JE (2008) Hematopoietic stem cell transplantation in childhood inherited bone marrow failure syndrome. Bone Marrow Transplant 41:127-132. doi:10.1038/sj.bmt.1705960.

Grewal SS, Kahn JP, MacMillan ML, Ramsay NK, Wagner JE (2004) Successful hematopoietic stem cell transplantation for Fanconi anemia from an unaffected HLA-genotype-identical sibling selected using preimplantation genetic diagnosis. Blood 103:1147-1151

Gross M, Hanenberg H, Lobitz S., et al (2002) Reverse mosaicism in Fanconi anemia: natural gene therapy via molecular self-correction. Cytogenet Genome Res 98:126-35. doi:10.1159/000069805.

Guardiola P, Pasquini R, Dokal I., et al (2000) Outcome of 69 allogeneic stem cell transplantations for Fanconi anemia using HLA-matched unrelated donors: a study on behalf of the European Group for Blood and Marrow Transplantation. Blood 95:422-429

Guinan EC, Lopez KD, Huhn RD, Felser JM, Nathan DG (1994) Evaluation of granulocyte-macrophage colony-stimulating factor for treatment of pancytopenia in children with fanconi anemia. J Pediatr 124:144. doi:10.1016/ S0022-3476(94)70271-3.

Habi O, Delisle MC, Messier N, Carreau M (2005) Lack of self-renewal capacity in FancC-/- stem cells after ex vivo expansion. Stem Cells 23:1135-41. doi:10.1634/stemcells.2004-0356.

Habi O, Girard J, Bourdages V, Delisle MC, Carreau M (2010) Correction of Fanconi Anemia Group C Hematopoietic Stem Cells Following Intrafemoral Gene Transfer. Anemia.

Hoehn H, Kalba R, Nevelinga R., et al (2007) Revertant Mosaicism in Fanconi Anemia: Natural Gene Therapy at Work. In: Schindler D, Hoehn H (ed) Fanconi Anemia A Paradigmatic Disease for the Understanding of Cancer and Aging, vol 15. Monogr Hum Genet, Basel, Karger, pp 149-172

Kapelushnik J, Or R, Slavin S, Nagler A (1997) A fludarabine-based protocol for bone marrow transplantation in Fanconi's anemia. Bone Marrow Transplant 20:1109-1110. doi:10.1038/sj.bmt.1701016.

Kelly PF, Radtke S, von Kalle C., et al (2007) Stem cell collection and gene transfer in Fanconi anemia. Mol Ther 15:211-219. doi:10.1038/sj.mt.6300033.

Li J, Sejas DP, Zhang X., et al (2007) TNF-alpha induces leukemic clonal evolution ex vivo in Fanconi anemia group C murine stem cells. J Clin Invest 117:3283-3295. doi:10.1172/JCl31772.

Liu JM, Kim S, Read EJ., et al (1999) Engraftment of hematopoietic progenitor cells transduced with the Fanconi anemia group C gene (FANCC). Human Gene Therapy 10:2337-2346. doi:10.1089/10430349950016988.

MacMillan ML, Wagner JE (2005) Hematopoietic cell transplantation for congenital bone marrow failure. Curr Opin Oncol 17:106-113. doi:10.1097/01. cco.0000152977.55175.5b

MacMillan ML, Wagner JE (2010) Haematopoeitic cell transplantation forFanconi anaemia - when and how? Br J Haematol 149:14-21. doi:10.1111/j.13652141.2010.08078.x

MacMillan ML, Blazar BR, DeFor TEMa., et al (2009) Alternate donor HCT for Fanconi anemia (FA): results of a total body irradiation (TBI) dose deesclation study. Biol Blood Marrow Transplant 15:3-4

MacMillan ML, Hughes MR, Agarwal S, Daley GQ (2011) Cellular therapy for fanconi anemia: the past, present, and future. Biol Blood Marrow Transplant 17(1 Suppl):S109-14

Marsit CJ, Liu M, Nelson HH, Posner M, Suzuki M, Kelsey KT (2004) Inactivation of the Fanconi anemia/BRCA pathway in lung and oral cancers: implications for treatment and survival. Oncogene 23:1000-1004. doi:10.1038/sj.onc.1207256.

McMahon LW, Walsh CE, Lambert MW (1999) Human alpha spectrin II and the Fanconi anemia proteins FANCA and FANCC interact to form a nuclear complex. J Biol Chem 274:32904-32908. doi:10.1074/jbc.274.46.32904.

Moldvay J, Schaff Z, Lapis K (1991) Hepatocellular carcinoma in Fanconi's anemia treated with androgen and corticosteroid. Zentralbl Pathol 137:167-170 
Muller LU, Williams DA (2009) Finding the needle in the hay stack: Hematopoietic stem cells in Fanconi anemia. Mutat Res 668:141-149. doi:10.1016/j.mrfmmm.2009.03.010.

Mulvihill JJ, Ridolfi RL, Schultz FR, Borzy MS, Haughton PB (1975) Hepatic adenoma in Fanconi anemia treated with oxymetholone. J Pediatr 87:122-124. doi:10.1016/50022-3476(75)80087-4.

Narayan G, Arias-Pulido H, Nandula SV., et al (2004) Promoter hypermethylation of FANCF: disruption of Fanconi Anemia-BRCA pathway in cervical cancer. Cancer Res 64:2994-2997. doi:10.1158/0008-5472.CAN-04-0245.

Nordin N, Lai M, Veerakumarasivam A., et al (2011) Induced Pluripotent Stem Cells: History, Properties and Potential Applications

O'Neill LA (2008) Primer: Toll-like receptor signaling pathways-what do rheumatologists need to know? Nat Clin Pract Rheumatol 4:319-327. doi:10.1038/ncprheum0802.

Ozenne V, Paradis V, Vullierme MP., et al (2008) Liver tumours in patients with Fanconi anaemia: a report of three cases. Eur J Gastroenterol Hepatol 20:1036-1039. doi:10.1097/MEG.0b013e3282f824e9.

Pagano G, Youssoufian H (2003) Fanconi anaemia proteins: major roles in cell protection against oxidative damage. Bioessays 25:589-595. doi:10.1002/ bies. 10283.

Pang Q, Fagerlie S, Christianson TA., et al (2000) The Fanconi anemia protein FANCC binds to and facilitates the activation of STAT1 by gamma interferon and hematopoietic growth factors. Mol Cell Biol 20:4724-4735. doi:10.1128/ MCB.20.13.4724-4735.2000.

Pasquini R, Carreras J, Pasquini M (2008) HLA-matched sibling hematopoietic stem cell transplantation for fanconi anemia: comparison of irradiation and non-irradiation containing conditioning regimens. Biol Blood Marrow Transplant 14:1141-1147. doi:10.1016/j.bbmt.2008.06.020.

Rackoff WR, Orazi A, Robinson CA., et al (1996) Prolonged administration of granulocyte colony-stimulating factor (filgrastim) to patients with Fanconi anemia: a pilot study. Blood 88:1588-1593

Raya A, Rodríguez-Pizà I, Guenechea G., et al (2009) Disease-corrected haematopoietic progenitors from Fanconi anaemia induced pluripotent stem cells. Nature 460:53-59. doi:10.1038/nature08129.

Rosenberg PS, Greene MH, Alter BP (2003) Cancer incidence in persons with Fanconi anemia. Blood 101:822-826. doi:10.1182/blood-2002-05-1498.

Rosenberg PS, Socié G, Alter BP, Gluckman E (2005) Risk of head and neck squamous cell cancer and death in patients with Fanconi anemia who did and did not receive transplants. Blood 105:67-73. doi:10.1182/blood-2004-041652.

Sala-Trepat M, Rouillard D, Escarceller M., et al (2000) Arrest of S-phase progression is impaired in Fanconi anemia cells. Exp Cell Res 260:208-215. doi:10.1006/excr.2000.4994.

Schindler D, Hoehen H (2007) Fanconi Anemia: A paradigmatic disease for the understanding of cancer and aging. Monogr Hum Genet, Karger 15:131-148

Socié G, Devergie A, Girinski T., et al (1998) Transplantation for Fanconi's anaemia: long-term follow-up of fifty patients transplanted from a sibling donor after low-dose cyclophosphamide and thoraco-abdominal irradiation for conditioning. Br J Haematol 103:249-255. doi:10.1046/j.13652141.1998.00968.x

Svahn J, Dufour C (2011) Fanconi anemia - learning from children. Pediatr Rep 3(s2): 18-20

Taniguchi T, Tischkowitz M, Ameziane N., et al (2003) Disruption of the Fanconi anemia-BRCA pathway in cisplatin-sensitive ovarian tumors. Nat Med 9:568-574. doi:10.1038/nm852.

Tolar J, Adair JE, Antoniou M., et al (2011) Stem cell gene therapy for fanconi anemia: report from the 1st international Fanconi anemia gene therapy working group meeting. Mol Ther 19:1193-1198. doi:10.1038/mt.2011.78.

Touraine RL, Bertrand Y, Foray P, Gilly J, Philippe N (1993) Hepatic tumours during androgen therapy in Fanconi anaemia. Eur J Pediatr 152:691-693. doi:10.1007/BF01955250

Tutt A, Bertwistle D, Valentine J., et al (2001) Mutation in BRCA2 stimulates errorprone homologydirected repair of DNA double-strand breaks occurring between repeated sequences. EMBO J 20:4704-4716. doi:10.1093/emboj/ 20.17.4704.

van Der Heijden MS, Yeo CJ, Hruban RH, Kern SE (2003) Fanconi anemia gene mutations in young-onset pancreatic cancer. Cancer Res 63:2585-2588

Velazquez I, Alter BP (2004) Androgens and liver tumors: Fanconi's anemia and non-Fanconi's conditions. Am J Hematol 77:257-267. doi:10.1002/ajh.20183.
Verlinsky Y, Rechitsky S, Schoolcraft W, Strom C, Kuliev A (2001) Preimplantation diagnosis for Fanconi anemia combined with HLA matching. JAMA 285:3130-3133. doi:10.1001/jama.285.24.3130.

Wagner JE, Eapen M, MacMillan ML., et al (2007) Unrelated donor bone marrow transplantation for the treatment of Fanconi anemia. Blood 109:2256-2562. doi:10.1182/blood-2006-07-036657.

Wagner JE, MacMillan ML, Auerbach AD (2003) Hematopoietic cell transplantation for Fanconi anemia. Thomas' Hematopoietic Cell Transplantation Oxford, United Kingdom Blackwell Publishing Ltd pp 1483-1506

Wang X, Andreassen PR, D'Andrea AD (2004) Functional interaction of monoubiquitinated FANCD2 and BRCA2/FANCD1 in chromatin. Mol Cell Biol 24:5850-5862. doi:10.1128/MCB.24.13.5850-5862.2004.

Zhang QS, Eaton L, Snyder ER., et al (2008) Tempol protects against oxidative damage and delays epithelial tumor onset in Fanconi anemia mice. Cancer Res 68:1601-1608. doi:10.1158/0008-5472.CAN-07-5186.

Zhang QS, Marquez-Loza L, Eaton L., et al (2010) Fancd2-/- mice have hematopoietic defects that can be partially corrected by resveratrol. Blood 116:5140-5148. doi:10.1182/blood-2010-04-278226.

doi:10.1186/1877-6566-6-1

Cite this article as: Shukla et al: Current and emerging therapeutic strategies for Fanconi anemia. The HUGO Journal 2012 6:1.

\section{Submit your manuscript to a SpringerOpen ${ }^{\mathcal{O}}$ journal and benefit from:}

- Convenient online submission

- Rigorous peer review

- Immediate publication on acceptance

- Open access: articles freely available online

- High visibility within the field

- Retaining the copyright to your article

Submit your next manuscript at $\gg$ springeropen.com 